\title{
LES NOTÍCIES MÉS ANTIGUES SOBRE ELS ORGUES DE LA CATEDRAL DE BARCELONA
}

\author{
Josep Baucells i Reig
}

L'objectiu del present treball consisteix, d'acord amb el títol, a presentar les notícies més antigues sobre els orgues de què disposà la Seu de Barcelona. Abasten els segles XIII i xIV. Bastant antigues, doncs, amb l'al-licient de poder estudiar un dels primers contractes per a la construcció d'un orgue que s'han conservat. Ens plau escriure el treball en ocasió de l'homenatge al doctor Frederic Udina, com a record de les vegades que, en veu baixa $i$ en alguna de les grans festes anuals, ell $i$ jo hem parlat de la catedral i de Barcelona parats al dessota mateix de l'orgue de la Seu barcelonina.

La circumstància d'ordre cientific que $m$ 'ha mogut a tractar aquest tema és la d'oferir als estudiosos els elements que la investigació ha descobert fins ara. Alguns són inèdits i altres han vist la llum una o diverses vegades, però en treballs que han silenciat sovint la font documental pertinent o la cota arxivística indispensable, o que no han donat a conèixer amb prou puresa

Nota - En la citació de les fonts documentals ens servim de les següents sigles:

ACB-O = Arxiu de la Catedral de Barcelona, Obra.

ACB-S = Arxiu de la Catedral de Barcelona, Sagristia.

ACB-A = Arxiu de la Catedral de Barcelona, Aniversaris. 
les dades extretes dels documents i, per consegüent, han afirmat punts inexactes.

Com a precedents de l'actual, podem esmentar, per ordre cronològic d'aparició, les notícies i treballs de sis autors: JAUME VILLANUEVA - cita el contracte de Martín Ferrándiz' - JOSEP Mas - relaciona, amb concisió i sense referències arxivistiques, els punts principals del tema que obren una gran porta ${ }^{2}-, \mathrm{SE}-$ BASTIẢ PUIG - publica íntegrament el contracte de Ferrándiz ${ }^{3}$-, HigINI ANGLÊs - repeteix les dades de Mas i dóna a conèixer en la redacció original el donatiu del bisbe Torrelles ${ }^{4}$, FrANCESC BALDELLÓ - amplia algunes notícies ja conegudes i n'ofereix alguna de nova $\mathrm{i}$ posa la font de la seva informaciós - , i

Viaje literario a las Iglesias de España, v. 17, Madrid 1851, p. 142.

2 «Nota histórica. L'altar de Santa Cecilia y les orgues de la Seu de Barcelonan, dins El Correo Catalán, de 27 de novembre de 1912. Dels segles xuI i xiv, parla de fra Guillem de Lacera del 1259, del contracte de Martín Ferrándiz el 1345, del Bisbe Guillem de Torrelles el 1368, dels orgues menors del rei el 1385 i de Pedralbes el 1390 i del treball de Jaume Ballester el 1392, amb la suposició d'uns orgues obrats per un tal N. Antonet. També esmenta, en un frase ràpida, l'orgue portàtil de la capella de Santa Eulàlia, com existent a les acaballes del segle xiv, sense concretar més. Mn. Mas tenia recollides, a més, altres notícies, buidades dels fons de l'Obra i de la Sagristia (no ho efectuà del dels Aniversaris), que escrigué en unes paperetes que estaren inc̀dites (estan guardades a l'Institut Municipal d'Història de Barcelona: fons Seu de Barcelona, capsa 23 titulada «Objectes», aplega "Orga», i les poguérem consultar de mà de l'amic Joan F. Cabestany, a qui regraciem la seva amabilitat). Amb relació a la nota històrica que publicà sobre els orgues, en cap fitxa del segle xiv no s'esmenta l'orgue de Santa Eulàlia i en una exposa l'encàrrec concretat amb Antonet a finals del xv; punts que comentem al final del present treball. En canvi, transcrigué el document de 19 de juliol de 1345 i mencionà un pagament lliurat a Martín Ferrándiz el mateix any, que nosaltres no haviem descobert.

${ }_{3}^{3}$ Episcopologio de la sede barcinonense, Barcelona 1929, p. 252 i ap. 114, pp. 480-481. També menciona la donació del bisbe Guillem de Torrelles, p. 260.

4 La música a Catalunya fins al segle xm, Barcelona 1935, pp. 84-85. Es refereix als orgues o reparacions de Guillem de Lacera, Martin Ferrándiz, Guillem de Torrelles - amb la cota arxivística - del rei, de Pedralbes i de Jaume Ballester, on retreu el treball de N. Antonet, basant-se en el treball de Mas.

"La seva obra principal és: "Órganos y organeros en Barcelona", dins Anuario musical 1946, pp. 195-237. Publica de nou les principals dades a «Los 
Àngel FẢBrega - es refereix al contracte de Ferrándiz i, amb intuició, a l'orgue petit de Devesa ${ }^{6}$. Podem afegir el fitxer manuscrit de BONAventura RIBAs, conservat a l'Arxiu Capitular, que recull notícies sobre Guillem de Lacera, Martín Ferrándiz, el bisbe Guillem de Torrelles i unes reparacions inespecificades obrades a partir de 1390 sobre els orgues de la catedral i la nominal del mestre Francisco Hispalense.

\section{FONTS}

Les notícies que donem a continuació, inèdites o no, totes són basades en la documentació guardada a l'Arxiu de la Catedral de Barcelona'. Es troben principalment en tres seccions: obra, sagristia i aniversaris. D'aquestes, és a dir, de les respectives administraciones depenien sovint els pagaments més usuals, per exemple, el salari dels organistes. És una llàstima que les sèries de llibres comencin el darrer quart del segle xiv i que no s'hagin conservat d'aquesta època els volumets dels albarans, als quals remeten algunes vegades aquells. Òbviament, la nostra investigació s'ha centrat en aquestes tres seccions.

órganos de la catedral de Barcelona. Breve reseña histórica», en un fulletó editat el 1952 amb motiu de la inauguració de l'orgue gran restaurat, si bé silencia J'orguener Antonet. En cada un d'aquests estudjs edjtà el fragment essencial del contracte de Martin Ferrándiz. I «Els "orgues menors" de la catedral basílica de Barcelona», dins Analecta Sacra Tarraconensia 37 (1965), pp. $375-$ 379 , on esmenta els orgues portàtils deixats a la seu pel rei i pel monestir de Pedralbes a final del segle XIv.

${ }^{6}$ La vida quotidiana a la Catedral de Barcelona en declinar el Renaixement. Any 1580, Barcelona 1978, pp. 54-55.

${ }^{7}$ Un primer contacte nostre amb el tema dels orgues, el tinguérem fa uns anys en ocasió de poder prestar un servei a l'amic Julio García Llovera, famós organista aragonès resident a Alemanya, el qual treballava llavors en la redacció d'un estudi documentat sobre la història de l'orgue a Espanya. Estudi que no podem citar perquè no ens consta que hagi estat editat. 
Conegut és que en la història orguenera de la catedral de Barcelona es donen tres categories d'orgues, denominades: orgue major, orgue mitjà i orgue menor, que equivalen a orgue molt gran, orgue de dimensions reduides i a orgue portàtil, tot i que el mitjà fos traslladable amb certes dificultats i que el menor no es pogués moure fàcilment. La present investigació no insistirà en aquest punt perquè no es cita encara el mitjà i, del petit, no n'hi ha prou dades per conèixer-ne amb exactitud el volum.

També és sabut que els termes usats en els documents - dels segles medievals, almenys - parlen sempre en plural: "òrguens», "òrgens», orgues, una manera de dir que equival al mode singular establert modernament amb relació a aquest instrument, en el llenguatge més usual o bé amb referència al conjunt; l'expressió en plural reflectia, sembla, la diversitat dels cossos que formen un orgue, i d'ella no es pot deduir l'existència de dos o més aparells alhora: per a cada orgue els documents parlen d'orgues.

És ben notori, aixi mateix, que els investigadors individualitzen els orgues i els identifiquen amb un nom concret, que correspon al del mecenes o del mestre orguener. Ara bé, no resulta gaire clar l'abast que aquesta forma de dir té en cada cas, com tampoc no ho és l'expressió «nou» amb relació a un orgue, llevat que aquestes maneres de dir convinguin bàsicament a afirmar que hi hagué una intervenció important, que pot anar des de la construcció d'un orgue nou en tot i per tot fins a la reforma d'un de preexistent. Reforma que inclou la restauració simple o bé la restauració i ampliació, o bé la reestructuració de tot l'aparell o bé la confecció d'un de nou que aprofita molts elements de l'antic. En aquest significat polivalent parlarem d'orgue nou, atès que la documentació no especifica més. Fins i tot en el cas del contracte de Martín Ferrándiz en què s'ordena l'aprofitament d'uns elements anteriors, els protagonistes no s'entretingueren a donar-ne detalls, sinó que el delegat capitular hi féu constar que tenia delegació ad faciendum fieri de novo in sede Barchinone organa, vel vetera in predicta sede existencia repa- 
rari. I si aquest document, el més complet dels segles XIII-XIV, no aclareix amb la precisió que voldriem el punt desitjat, encara resta molt més fosc en les altres notes documentals, breus i concises. Diríem que la referència a obres sobre l'orgue, sense més apel-latius, ubicat en un mateix lloc, importa un remanament més o menys important que permet parlar d'orgue nou.

Finalment, hem de tenir en compte la confusió que pot néixer de no detallar-se en la documentació l'ofici exacte de les persones més estretament relacionades amb l'orgue i que la lexicografia moderna classifica en orguener, l'artista constructor i en organista, el mestre músic. La documentació investigada és prou clara respecte d'això: cada actor surt en un treball concret i res no obsta que en altres llocs o moments, desconeguts o coneguts, exercís també l'altre, és a dir, que una sola persona fos organista i orguener alhora. Diem només que això a la catedral de Barcelona no consta, en el periode precitat.

\section{QUADRE D'HONOR}

Reportem aqui els noms de les persones que estan més relacionades amb els orgues de la Seu barcelonina. Val la pena de tenir-los presents amb un cop d'ull.

\section{Benefactors}

Abans de 1259 - Guillem de Lacera, cavaller i frare de l'ordre del Sant Sepulcre.

Abans de 1368 - Guillem de Torrelles, bisbe de Barcelona.

\section{Constructors}

Vers 1320 - Berenguer Pla, beneficiat de la Seu.

1345 - Martín Ferrándiz, mestre d'orgues, de Toledo. 1383 - Antoni Rovira, àlias Largo modo. 
1385 - 1389 - Pere Devesa, mestre d'instruments, de Barcelona.

1390 - Francisco Hispalense, mestre d'orgues, de Sevilla.

1397 - Pere Creu, monjo del monestir de Ripoll.

Organistes

1377 - 1382 - Antoni Gran.

1378 - 1403 - Jaume Ballester.

1379 - 1391 - Andreu Pasqual.

\section{LORGUE MAJOR}

\section{Situació}

L'orgue major i principal de la catedral de Barcelona ha ocupat sempre el lloc on es veu actualment en l'obra gòtica: l'espai superior del braç que a manera de creuer dóna accés a la port de Sant Iu, al cantó de llevant, segons la nomenclatura convencional barcelonina (nord-est, exactament). Ocupa un indret situat entre l'absis i la nau, a un nivell una mica superior al pis del trifori que recorre aquesta. Té dues obertures de comunicació: l'escala principal que ascendeix ràpidament i amb graons elevats des de tocar el cancell de la porta de Sant Iu per mitjà d'una porta practicada al mur meridional, i la porta que uneix l'orgue i el trifori, a la qual s'arriba bé sigui per l'escala del baptisteri, bé sigui per la del campanar, bé sigui modernament per l'ascensor de la capella de santa Llúcia. Des de l'escala de l'orgue, en un replà bastant amunt, una portella donava entrada a un compartiment que ocupà la part alta de la «tribuna» reial després que aquesta fos suprimida.

Aquesta situació col-loca l'orgue en l'espai immediat a la capella de Santa Agnès (avui de la Mare de Déu de Montserrat), que és la primera de la nau, la qual cosa ens permet suggerir 
que ocuparien una mateixa disposició en l'obra romànica, segons ho afirma un estudi recent, i sembla deduir-se de la relació estreta que entre orgue i santa Agnès marcà el primer benefactor conegut.

\section{Primera notícia i primer benefactor}

Que la catedral de Barcelona estaria dotada d'un orgue des de temps antics és una suposició evident, malgrat que cap document no en parli. Quan la seva existència surt a la llum té aparences d'una creació ex novo, que hem d'entendre segons el que hem exposat abans: reforma i ampliació de l'orgue precedent. El text, però, no ho diu ni ho dóna a entendre.

La primera notícia es remunta a un temps abans de l'any 1259 i fa referència a la construcció d'un orgue, ordenada i sufragada per Guillem de Lacera, un personatge barceloni, ric i pietós.

Uns mesos després, quan l'obra de l'orgue era acabada, Guillem, preocupat per la seva conservació, deixà establert quina persona n'era responsable i disposà els mitjans econòmics indispensables. Ho féu constar en un document signat l'l de juny de 1259, que no s'ha conservat. També ordenava la fundació d'un benefici presbiterial a l'altar dè santa Agnès de la catedral, benefici que dotava convenientment, a fi que exercis les funcions religioses comunes, fes construir l'altar de santa Agnès i vetllés per la conservació de l'orgue. La clàusula sobre això, sortosament conservada, diu textualment:

Item quandocumque necesse fuerit faciat meus sacerdos abtari et refici organa, que ego feci fieri in sede, et teneatur expendere duos aureos singulis annis, illos si necesse fuerit in predictis expendat; quod autem minus necesse fuerit, dicto sacerdoti accrescat $^{8}$.

${ }^{8} \mathrm{ACB}-\mathrm{A}$, Liber clausularum anniversariorum, f. $43 \mathrm{v}$; el fragment sencer, f. 43-43v. Al marge, un escrivà del segle xIv afegi una anotació, inacabada, que sembla indicar un dubte sobre el compliment del que s'hi ordena. Advertim que el document d' 1 de juny de 1260 és presentat erròniament com a testament en algun treball, on, a més, s'assenyala el mes de gener, equivocat també. 
Veiem, doncs, que el sacerdot beneficiat de santa Agnès tenia l'obligació, si era el cas, d'esmerçar fỉns a un màxim de dues monedes d'or a l'any en la reparació i adaptació de l'orgue. Aquest deure, deixat així al criteri del clergue obtentor del benifet, originaria conflictes d'apreciació i oportunitat amb els responsables de l'orgue. Per això, en un moment indeterminat del segle xIv - possiblement en el traspàs del temple romànic al gòtic - fou fixat en una aportació invariable anual, consistent en el lliurament de 9 sous amb motiu de Nadal. La nova pràctica, la trobem registrada per primer cop l'any 1383: «Item fa lo rector de Santa Agnès per los òrgens en le feste de Nadal, VIIII s. $n^{y}$. Anotacions semblants es repeteixen al peu de la lletra gairebé els anys següents, cosa que demostra la constància del dit pagament i que revestia el concepte de remerciar una tocada especial o més lluïda la diada de Nadal o bé com a estrena d'aquesta festa. Per una raó o altra, continuà anys $\mathrm{i}$ anys el lligam entre l'orgue major i el beneficiat de santa Agnès.

Serà bo que diem alguna cosa del primer benefactor dels orgues de la catedral. Guillem de Lacera estava unit en matrimoni amb Guillema, i tingué dos fills i una filla. El fill gran i hereu, d'igual nom que el pare, Guillem, el segon, Berenguer, i la noia, Elisenda. Poc temps després d'haver-se enllestit la construcció de l'orgue, Guillem sentí la vocació religiosa i, un cop ordenats els assumptes temporals en el testament de 23 de març de 1260 i amb permis de la seva esposa, ingressà al monestir de Santa Anna de Barcelona, de l'orde canonical del Sant Sepulcre. Des d'aquí, ja novici, el 21 d'octubre de 1264 ordenava no sols la ratificació de la fundació decretada cinc anys abans sinó que la redotava amb l'assignació de noves propietats, de manera que, a més de sis morabatins censals comprats al preu de 240 , hi destinava en aquell moment unes cases de Barcelona, dos masos

7. ACB-S, Llibre d'administració de 1383-1385, f. 17v. La mateixa frase amb poques variacions es repeteix al f. 18, i als llibres de 1385-87, f. 15 i 16; de 1389-91, f. $20 \mathrm{v}$ i $21 \mathrm{v}$; de $1391-93$, f. $20 \mathrm{v}$ i 22 , on es consigna un morabati, moneda comptable equivalent a 9 sous; $i$ de 1399-1401, f. $4 \mathrm{~V}$ amb el redactat diferent: «Item resebi d'en Nicolau Perer, rector de Sent (sic) Agnès, per sens que fa a la sacristia per los òrguens, IX s.n 
de Tiana $\mathrm{i}$ altres béns. Aquest document sí que s'ha conservat i s'hi fa al-lusió al de $1259^{\circ}$. Els dos fills barons, l'1 de juny de 1263 , amb permís del pare i per tal de conservar la bona harmonia entre germans, decidiren el repartiment de les assignacions que els féu el pare en l'esmentat testament ${ }^{11}$. I la filla es casà amb Bernat Durfort i, en un enfrontament amb el seu sogre Berenguer Durfort per motius econòmics, obtingué un arbitratge favorable a la seva postura $\mathrm{i}$ el rei Jaume I intervingué fent-li costat ${ }^{12}$. Del benefici de santa Agnès, se n'aprofitaren durant uns anys uns clergues de la mateixa familia.

\section{Segona notícia i primer orguener}

Passats cinquanta anys de la reforma patrocinada per Guillem de Lacera, l'orgue necessitava altra vegada una restauració d'importància i el capítol l'encomanà a Berenguer Pla o Desplà, beneficiat de la mateixa seu. Devia ser un any de la segona desena del tres-cents, proper al 1317, en què coneixem l'existència d'un beneficiat del mateix nom ${ }^{13}$, una data situada bastant al mig de la primera notícia i de la tercera, i que correspon bé a la dada que d'ella ofereix la segona notícia, que diu literalment:

És emprès... que lo dit mestre Martí... faça tres vies de punts al través més que no eren en aquels que ja eren en la dita Seu, los quals obrà en Berenguer des Pla, beneficiat en aquela.

La menció que el document de $1345^{14}$ fa de l'orgue anterior no arriba, doncs, al temps de Guillem de Lacera per dues raons:

${ }^{10}$ ACB, Dotaliarum I, f. 141v-143.

" $\mathrm{ACB}$, perg. 1-1-1493 i perg. 4-93-14. L'hereu Guillem, el mes de març de 1249, contragué matrimoni amb Guillema, filla de Ferrer Suau.

${ }_{12}$ ACB, Cartes reials, C.-15, C.1-9, C.5-5, C.1-27, C.5-36, C.5-9. Cf. José Ouneras Caminal, Cartas reales (siglos XII-XV), Barcelona 1946, núm. 33 , 35, 38-41.

${ }_{13}$ Arxiu Diocesà de Barcelona, Regisire Comú III, f. $100 \mathrm{v}$.

${ }^{14}$ Cf. nota 16. Baloecló (Órganos, p. 205) el situa a mitjan segle xirr i 
la primera, la inclusió de la frase en el document denota una proximitat relativa en el temps entre la reforma de 1345 i l'anterior perquè es mantenia viu el record del treball darrer - cosa totalment d'improbable veracitat de mediar un espai gairebé de cent anys - i la segona, perquè en descobrir l'activitat d'un beneficiat Berenguer Pla el 1317 -tot i que no pot negar-se la possibilitat de l'existencia de dos beneficiats del mateix nom en anys diversos i simultaniament-ens adonem que cau a una distància mitjanera d'uns trenta anys, que és el temps màxim que un orgue rutllava sense dificultats greus, com veurem tot seguit.

Que es tracta d'un orguener i no d'un benefactor, ho afirmem d'acord amb «obrà», el verb de la frase adduida, diferent de «féu obrar» i en consonància amb la categoria econòmica d'un beneficiat, el mitjà que possibilitava el pagament de les despeses que comportava una reforma important, com fou la seva. D'aquesta, només sabem que consistí a dotar l'orgue amjor «de vies de punts al través».

\section{Tercera noticia: contracte de Martín Ferrándiz.}

Vers l'any 1344 el bisbe fra Ferrer d'Abella i el capítol, a la vista que l'orgue no funcionava bé, es decidiren a cercar la solució i encomanaren l'inici de les gestions pertinents als canonges Guillem de Torrelles i Ferrer Peiró. La missió d'aquests resultava infructuosa fins que descobriren Martín Ferrándiz, «maestre de òrguens», és a dir, constructor d'orgues, de Toledo, que era a Barcelona, de passada o per haver estat cridat expressament pels dits canonges o per altres persones - no ho sabem-, i s'avingueren en un pre-acord. Llavors, en comunicar l'estat de la qüestió al nou bisbe i al capítol, aquests dictaren unes directrius el 19 de juliol de 1345 en virtut de les quals es concretava el sistema de finançament: a càrrec de les administracions de l'Obra, la Sots-sagristia i la Caritat en parts iguals, i donaven

l'identifica, per tant, amb l'obra sufragada per Lacera, basant-se en uns documents inèdits de mossèn Mas. Al final del treball toquem aquest punt. 
plens poders als comissionats en conjunt o individualment. En el document ${ }^{15}$, es reporten els detalls esmentats sobre els passos menats anteriorment des del temps de fra Ferrer d'Abella (morí el 21 de desembre de 1344 a l'Arboç, on era de visita pastoral) i sobre el mal estat de l'orgue antic, de manera que els delegats tenien poder per convenir ipsa organa reparari vel de novo fieri facere.

Arribats a un acord total, les parts implicades redactaren el document del contracte ${ }^{16}$ el 23 de juliol de 1345, que signà d'una part l'esmentat mestre i de l'altra el canonge Ferrer Peiró, el qual actuava a la vegada en nom del seu company de comissió - absent aquell dia- i del bisbe i el capítol segons els termes de la delegació rebuda quatre dies abans. El bisbe, el valencià fra Bernat Oliver, de l'orde de Sant Agustí, estigué a Barcelona el temps que tardaren a desenvolupar-se les gestions, l'acord i l'execució del nou orgue: arribà a principis de $1345 \mathrm{i}$ marxà a mig any del següent, quan l'aparell nou acavaba de ser instal-lat a la Seu, si es complí amb exactitud el termini prescrit en el pacte, com cal suposar.

El pacte convingut per les dues parts és inserit en el document citat i té la particularitat d'estar redactat íntegrament en català, la qual cosa ens fa pensar que debia ser una llengua coneguda del mestre i preferible al llatí, en què és escrita la resta del document. El pacte inclou en diversos capítols les característiques tècniques, els materials, el sistema, el termini, el pagament i unes condicions especials.

Sobre les característiques tècniques podem dir que l'orgue havia de constar de set vies de punts al través, de set o vuit migs punts i de 309 canons o tubs, dels quals, en la primera tercera part de les vies, set a cada una de les quatre primeres vies on eren els

15 Publiquem el text complet i una nota explicativa a l'apèndix 1.

${ }^{16}$ ACB-O, perg. 3. De la minuta només es conserven fragments en les restes dels darrers fulls del volum del notari Pere Borrel, Manuale de 9 kalendas aprilis ad 17 kalendas augusti 1345, que s'estén al dia nou d'agost en realitat; entre els dos textos es donen variacions accidentals, en la part que encara pot llegir-se. Publiquem el text complet a l'apèndix 2. També l'edità Puig (cf. nota 3) i Baldelló (cf. nota 5) donà a conèixer els capitols en català. 
bordons, i dotze a les altres tres vies; en la segona part, setze canons a cada via, i en la restant tercera part, vint canons a cada via de punts. Constaria també de caixa obrada amb bona fusta, però amb absoluta simplicitat (ab obratge pla) i tancada per dalt, de manxes i de clavilles. No es dóna cap altra indicació.

En la construcció, el mestre utilitzaria materials de bona condició: plom, estany, fusta i cuir. De la fusta que entrava en la construcció de la caixa, se n'especifiquen tres qualitats: bona, vella i seca; la de les manxes rep la denominació de post i havia de ser bona i ferma; i la de les clavilles consistiria en fusta de boix o de ginjoler, bona, ferma i estable. I, sobre el cuir de les manxes, es féu constar que seria de cérvol, ben adobat.

Quant al sistema, s'estipularen dues clàusules principals: que el mestre treballaria a la ciutat de Barcelona, és a dir, en un obrador o local escollit per ell dins la ciutat, i que ell es preocuparia de contractar el servei dels mestres que treballaven el plom, l'estany i la fusta.

Sobre el termini, se n'assenyalà un de precís: un any complet des del dia que començaria a treballar-hi.

La part econòmica fou convinguda en imports i en unes formes concretes. Els imports serien: 80 lliures com a preu total del treball i 40 sous mensuals en concepte de la seva despesa (és a dir, lloguer de l'obrador, vestits i menjar), que sumarien al final vint-i-quatre lliures (l'equivalent al sou d'un rector de poble menut en aquella època). Són pagues netes per al mestre, que percebria la grossa fraccionadament: cent sous el mateix dia de signar el contracte i la resta en donar-se per acabada la feina. Els imports dels sous dels esmentats mestres ajudants i de la compra de materials anaven a compte de l'administració capitular per mitjà del mestre.

Com a condicions especials hi ha: primer, treballaria en exclusivitat en la construcció d'aquest orgue, llevat que obtingués llicència en contrari dels canonges comissionats; en el cas d'incompliment cauria en la pena de presó sota la vigilància de l'oficial de Barcelona (és a dir, la presó episcopal). Segon, l'obra feta seria bona, sonorosa, ferma i estable, i executada amb tot el saber i poder del mestre. Tercer, el trasllat de les peces obrades 
i el seu muntatge al lloc de la catedral, que li indicarien els responsables, anaven completament a càrrec del mestre. Quart, quan l'orgue seria acabat complidament $i$ posat a la seu, la feina es donaria per finida, i cobraria la resta de l'import fins a les 80 lliures pactades (és a dir, 75).

Martín Ferrándiz inicià tot seguit els treballs de recomposició o construcció de l'orgue, dels quals en lleven fe dues àpoques de cobraments rebuts pel mestre: una inespecificada del 25 de novembre i una altra del 16 de desembre amb l'import de 74 sous ad opus expedicionis dictorum organorum, destinat al manteniment del mestre, sens dubte ${ }^{17}$.

\section{Quarta noticia $i$ segon benefactor}

Entre 1361 i 1369 , en què pontificà a Barcelona el bisbe Guillem de Torrelles, aquest prelat obsequià la Seu amb un orgue gran i bonic. Ho féu constar després en un document de 8 de juliol de $1368^{18}$, que inclou també el donatiu de llibres i objectes preciosos, en els termes següents:

17 ACB, Notaria, Pere Borrell, Manuale de 6 kalendas augusti 1345 ad 13 kalendas ianuariï eiusdem anni, f. $125 \mathrm{v}$ i $188 \mathrm{v}$. A la primera citació sols s’escrivi la primera ratlla i part de la segona, i a l'altra citació, que era completa, la humitat i la desfeta subsegüent del paper han perjudicat l'estat de la tinta del fragment conservat i han fet perdre la part superior del full on es continuava el text. Transcrivim el fragment del f. 188v: «[Die mercurii $\mathrm{XVII}^{\circ} \mathrm{ka-}$ lendas ianuarii anno predicto (1345)]. Ego Martinus Ferrandis, magister organorum, civis Tholotane, confiteor et recognosco vobis venerabili et discreto Ferrario Payroni, canonico Barchinone, quod solvistis michi bene et cetera, in manus scilicet discreti Guillelmi de Chorro, beneficitati in Sede Barchinone, septuaginta quatuor solidos monete barchinonensis de terno, quos vos nomine operis dicte Sedis debebatis michi solvere de presenti ad opus expedicionis dictorum organorum, et que sunt de peccunie quantitate que michi promissa fuit dari racione dictorum organorum. Ideo renunciando excepcioni non numerate et non solute peccunie, nec doli, mali et racioni in factum et omni alii iuri, racioní et consuetidini contra hec repugnantibus, facío vobís nomine predicto de dictis septuaginta / .... .

18 ACB, Notaria, Pere Borrell, Manuale a 12 maii 1366 ad 28 februarii 1371 , f. 98v. El full del plec on consta la minuta fou enganxat malament al moment 
Item organa magna et pulcra [que] fieri facimus in ipsa ecclesia Barchinone.

Ell ordenà i pagà, doncs, la construcció d'un orgue que, en ser qualificat de gran, cal identificar amb l'orgue major de la seu, i no amb un altre independent d'aquest. Ara bé, què havia passat perquè l'orgue ampliat el 1345 necessités una obra de reparació important? Un fet catastròfic, un llamp per exemple, l'havia espatllat? El bisbe impulsà una nova ampliació d'aquell? De manera simple, sembla que els materials bons i estables no resistien gaire més de vint anys, els que van de l'obra de Guillem de Torrelles a la de la reforma anterior (1345), d'una banda, i a la de la posterior (1385), de l'altra, com veurem tot seguit. La vida d'un orgue era molt curta.

\section{Cinquena noticia: dos orgueners i reparacions}

Al cap de vint anys escassos de funcionar - el temps crític-, l'orgue de Guillem de Torrelles no anava prou bé i es presentaren unes avaries, de no gaire envergadura, que no foren resoltes ni ràpidament ni amb energia o seguretat. La catedral, per consegüent, passà una temporada que no pogué disposar de l'orgue amb la seguretat mínima. Tenim notícia de quatre o cinc reparacions d'importància petita, que no corresponen a la falla greu de l'instrument, tant que obligà els responsables a demanar orgues en préstec i a proveir-se d'un orgue menor.

La primera reparació d'aquesta sèrie la portà a terme l'any 1383 l'orguener Antoni Rovira, mestre català sens dubte, força conegut en els ambients musicals d'aquell temps, que el batejaren amb el sobrenom de "Largo modo», que pot reflectir alguna de les seves aficions en el ritme musical o en la manera de

de relligar el volum i no es llegeix «que» ni els mots inicials de totes les ratlles al cantó del llom. Tots els llibres i objectes del bisbe, menys l'orgue - naturalment en ser inamovible-, retornaren en qualitat de préstec a la mà del donador, quan era prelat de Tortosa, I'11 de juliol de 1369. Ib., f. 99v-100. 
comportar-se en el treball; no es tractaria de gran cosa perquè el mes d'agost cobrava només 9 sous ${ }^{19}$.

La segona reparació, comparable a aquella si ens fixem en l'import, fou anotada així:

Item done $a \cdot n$ Pere Devesa per manament dels sagristans, per adobar los òrgens per ço que sonasen en le feste de Nadal, e feu-hi portar III parells de manxas de las fusinas, $\mathrm{X} s.\rangle^{20}$.

Va aconseguir-se, però, que la celebració nadalenca tingués el suport insubstituible de l'orgue. Era l'any 1389. És mèrit de l'esmentat Devesa - constructor de l'orgue menor, direm en un altre apartat-, gràcies a adaptar-hi tres parells de manxes noves portades directament de l'obrador del fonedor.

Altra vegada, en ocasió de les festes de Nadal, amb la seva capvuitada i els Reis del 1391, s'efectuaren treballs, sota la direcció de l'organista Jaume Ballester, que importaren la utilització de dues francisses o frontisses, sis barres de ferro, una anella amb clau i la corda de l'esquella o campana que hi passava, un «mortel» o martell, claus i ferramenta menor, comprat al ferrer Joan Baral al preu total d'1 lliura, 8 sous i 3 diners, que l'organista recobrà el gener de $1392^{21}$. Per a aquesta feina o per a una de posterior se serviren de punxes, al preu d'1 sou, import del qual el mateix Ballester es reféu el 15 de maig següent ${ }^{22}$.

19 ACB-S, Llibre d'administració de 1383-1385, f. 61. El text és: "Item done a.n Antoni Rovira àlias Largo modo per adobar los òrgens, XVIJI s,»

${ }^{20}$ ACB-S, Llibre d'administració de 1389-1391, f. 75v.

${ }^{21}$ ACB-S, Llibre d'administració de 1391-1393, f. 75: «Item dimarts a IX del dit mes [gener 1392] done [a] en Jacme Balester per mesions que avie fetes en adobar los òrguens majors. Primo comprà d'en Johan Baral, farrer, dues francises, II s. Item per sis baulons de ferro a rahó de VIII dr. la pesa, IIII s. Itern per IIII francises dels òngueus menors, a rahó la pesa de II s., leven VIII s. Item tatxes, III dr. Item una anela a manera de clau per on pasa la corda de la squaleta, VI dr. Item un mortel, I s. VIII dr. Item la corda de la sqela, IIII dr. Item li done per dos jornals he mig que lo fuster ab dos fadrins hi avien fets, he per fusta; item per clavó, XXXI s. VI dr. Munte enfre tot II 11. VIII s. III dr.

${ }^{22} \mathrm{Id}$, ib., f. $79 \mathrm{v}$. 
Novament, la proximitat de les grans festivitats de desembregener urgí una quarta reparació petita, la qual consistí en l'adquisició d'una albadina o pell que (en una manxa, segurament) enganxà bé amb aiguacuit el fadrí d'en Llopart el desembre de $1392^{23}$.

Per comprendre l'acumulació de treballs de restauració entorn del Nadal, s'ha de tenir en compte la importància litúrgica d'aquelles festes i, a més, les celebracions populars, denominades «jocs» en el llenguatge de l'època o representacions - la Sibil-la, Sant Esteve, etc.- que s'efectuaven a l'interior de la catedral de Nadal a Reis i que arribaven llavors a la seva màxima esplendor. D'aquí, que el capítol fes l'impossible per disposar d'orgue.

Mentrestant, el canonge Berenguer Desfeu o Feu, responsable capitular de l'orgue, prou que, en cercar la solució definitiva a l'estat compromès de l'instrument, es movia i fins i tot sol-licità el parer tècnic d'altres entesos, un dels quals, mestre d'orgues, vingué expressament de Manresa el 1389-1390:

per veer - llegim a l'apuntament - los òrgens major què havien mester, e fes ab ell avinense de adobar,

per la qual cosa li pagaren 3 florins, és a dir, 1 lliura i 3 sous $^{24}$. I un altre mestre el 1397 es desplaçà del monestir de Ripoll, com diem en tractar de l'orgue menor.

Al final, les reparacions feren efecte i l'orgue del bisbe Torrelles continuà funcionant una colla d'anys.

${ }^{23}$ ACB-S, Llibre d'administració de 1391-1393, f. 85v: «Item divendres a XX del dit mes [desembre 1392] compre una albadina ops dels òrguens majors, costà I s. II dr. Item done al fadri d'en Lonpart enfre aygua cuyta e son trebal, qui ho adobà, I s.; leve II s. II dr.n

24 ACB-S, Llibre d'administració de 1389-1391, F. 50. La nota copiada textualment diu: «Item done a mossèn Berenguer des Feu, los quals ell ja havie donats al mestre dels òrgens, que havie fet venir de Manresa per veer los òrgens majors quẻ havien mester, e que fes ab ell avinerise de adobar, dóna-li III florins = I 11. XIII s.». Aquesta nota figura en un apartat que no assenyala el temps exacte dins el periode de maig de 1389 a abril de 1391 . Advertiment que val per a les altres notes extretes del mateix llibre i del mateix apartat. 
No és sinó fins a la darreria del segle xIv que salta a la llum pública el nom del primer organista de la Seu, ja que de les persones esmentades als apartats anteriors, només cabria la possibilitat de ser-ne Berenguer Pla, beneficiat, però l'única font documental que el dóna a conèixer el presenta en qualitat d'orguener, com hem vist.

Quant a l'organista, la situació el darrer quart dels tres-cents, podem afirmar que era una persona contractada, no lligada, doncs, ni al cos capitular ni a la catedral en general mitjançant un benifet; que el contracte tenia caràcter merament temporal; que en l'ofici podien fer torns mestres diversos, que el seu sou anual pujava a 120 sous i que eren laics, és a dir, persones no eclesiàstiques. Ho basem en uns documents, el contingut dels quals és redactat en uns termes massa concisos, no ampliable ni contrastable amb les notes autògrafes dels organistes que figuraven en els llibres dels albarans, perquè malauradament no s'han conservat.

La llista dels organistes de la catedral de Barcelona s'obre el $1377 \mathrm{amb}$ el nom d'Antoni Gran, i tot seguit continuen els de Jaume Ballester i Andreu Pasqual. Cobraven 120 sous com a salari anual, entesa l'anualitat sovint d'acord amb el sistema administratiu de la Seu, que anava d'1 de maig a 30 d'abril. Aquest import - de quantitat igual a la que cobrava en un mes un mestre fuster- no donava per viure: les sis lliures salarials són lluny de les vint que eren considerades mínimes. Així que els organistes devien compartir el seu ofici entre la catedral $i$ altres esglésies, o bé el compaginaven amb altres feines. Hi hauria la possibilitat que s'acostés a aquell minim si, com passava en altres activitats del mateix temple - les representacions, per exemple-, el sou es formava amb l'aportació de l'obra, la sagristia i els aniversaris en parts iguals; llavors resultava un sou de divuit lliures, a les quals caldria sumar alguns extres, com els 9 sous que pagava cada any el dia de Nadal el beneficiat de Santa Agnès, com hem dit repetides vegades.

Antoni Gran, Jaume Ballester i Andreu Pasqual són els noms 
dels tres organistes que en el període de maig de 1377 a abril de 1379 actuaven a la catedral, d'acord amb les anotacions registrades en un mateix llibre ${ }^{25}$, en un apartat que no especifica el temps exacte dels respectius pagaments, és a dir, actuacions:

Item pague a $\cdot \mathrm{n}$ Antoni Gran per tocar los les (sic) òrgens, CXX s., an $\cdot \mathrm{i}$ alberà.

Item pague a en Balester e Antoni per sonar los òrgens per VII mesos per tal con los hi tolgeren, e avien servits, e an $\cdot \dot{i}$ alberà, LXXs.

Item done en Pasqal per tocar les òrgens, LX s.

Temps, però, que correspon a Gran sol de 1377 a principi de 1378; a Gran i a Ballester, en conjunt, set mesos de 1378; i a Pasqual, sis mesos de 1379. Deduïm els respectius períodes del lloc que ocupen els esmentats textos en l'apartat documental, amb relació especial al altres apuntaments que porten data o fan referència a alguna festivitat, la qual cosa permet establir amb seguretat gairebé absoluta els períodes d'actuació dels tres organistes catedralicis.

Antoni Gran, a més del període citat, també fou organista l'any 1382 i cobrà el consuet salari ${ }^{26}$; es degué retirar de la seu, ja que no surt més el seu nom.

Andreu Pasqual hi actuà almenys quatre temporades: l'esmentada de 1379 , una de dotze mesos del $1386^{27} \mathrm{i}$ una altra d'igual durada el $1389^{28}$, amb el sou complet de 120 sous cada vegada, i una quarta de nou mesos entre 20 de gener i 20 d'octubre de 1391, amb import de 95 sous $^{29}$.

25 ACB-A, Llibre d'administració de 1377-1379, f. 60, 61 i 62.

${ }^{26}$ ACB-A, Llibre d'administració de 1381-1383, f. 15v. El text és una repetició del del llibre de 1377-1379, f. 60.

${ }^{27}$ ACB-A, Llibre d'administració de 1386-1387, f. 73: "Item done a.n Andreu Pascall per tocar los orgens, CXX s.m. El registre correspon a finals de 1386, abans de Nadal, encara que la nota no digui res sobre cronologia.

${ }^{28}$ ACB-A, Llibre d'administració de 1389-1391, f. 67: «Pague a-n Andreu Pascall per tocar los òrgens de $\mathrm{I}$ any, an-i alberà, CXX s.». La despesa és en l'apartat de 1389-1390, peró tot abona l'exactitud del primer any.

29 ACB-A, Llevador de 1391-1393, f. 39v: Item paguem (sic) a-n Andreu 
Jaume Ballester també sumà quatre contractes: el primer el 1378 , el segon, que durà exactament un any, sis mesos i deu dies, del 21 d'octubre de 1391 al 31 d'abril de 1393, i rebé 183 sous i 4 diners $^{30}$, en correspondència matemàtica als 120 anuals; el tercer, el 1395-1396, i el quart, el 1396". A ells podem afegir un cinquè contracte - fora del període estudiat-, el $1402-1403^{32}$, a partir del qual desapareix el seu nom.

Tenim, així, que els esmentats tres organistes omplen 27 anys d'història musical de la seu barcelonina: Antoni Gran ocupa sis anys entre 1377-1382, Andreu Pasqual té tretze anys entre 1379 i 1391 i Jaume Ballester abraça 26 anys entre 1378 i 1403. Aquest darrer organista els últims deu anys fou, de fet, l'únic i actuaria cada any, de manera que el redactor de la nota de 1402 es refereix al salari que «li ha de donar cada any l'administrador dels aniversaris", per tenir un contracte renovat anualment o de caràcter indefinit. Entrat ja el nou segle, trobem nous organistes.

\section{Notícies complementàries}

Sota aquest epígraf incloem unes quantes dades documentals relacionades indirectament amb l'orgue major de la Seu.

La majoria fa referència a l'indret on era - i és-l'orgue ma-

Paschal per tocar los òrgens de IX meses qui finaren en octobri del any MCCC.XXI, XCV s.", amb un error en les xifres de l'any que porta una segona $\mathrm{X}$ en lloc de $\mathrm{C}$. El dia del mes és una deducció matemática del període que segui j que fou encomanat a Jaume Ballester, segons la nota 28.

${ }^{30}$ ACB-A, Llevador de 1391-1393, f. 39v: «Item pague al sènyer en Jacme Balaster per tocar los òrgens de XXI de octobri entrò al primer die de may de XCIII, qui són I any VI meses e X dies, CLXXXIII s. IIII dr.»

${ }^{31}$ ACB-A, Llibre d'administració de 1395-1397, f, 36v: «Item pague a-n Jacme Ballester, qui toque los orguens de la Seu per salari de son offici, e fé me'n alberà de sa mà, CXX s.m, i f. 84: «Item patgue (sic) a-n Jacme Ballester, administrador dels òrguens, per salari seu de son offici per aquest any, an $i$ alberà, CXX s.n.

${ }_{32}$ ACB-A, Llibre d'administració de 1402-1403, f. 48v: «Item foren pagats a mossèn en Jacme Balester per tocar los òrgens, los quals li ha a dar quescun any lo administrador dels aniversaris, an $\mathrm{i}$ alberà, CXX s.n. 
jor i a través del seu contingut s’albira la preocupació del capítol a assegurar el bon estat d'aquest instrument, tan gran i tan delicat. Com que calia vetllar l'entorn, el març de 1386, els fusters Bernat Moragues i Antoni Alamany, durant un dia i mig i dos respectivament, treballaren en la reparació de la trapa que cobria el sostre de la sala dels orgues (per on pujaven les campanes al pis del cloquer bastit directament a sobre) i en el canvi del drap de canemàs - sistema provisional de les vidrieres que obligava a substitucions freqüents a causa de la fragilitat del material- que tapava l'ull buit de la finestra obrada a la part superior de la paret que dóna a la nau ${ }^{33}$. Així com, el juny de 1390, en el decurs d'una de les reparacions en què els canons o tubs de l'orgue foren posats al corredor del trifori, calgué després escombrar el sector de sobre la capella de sant Llorenç ${ }^{34}$ (que en fa un de sol amb el de la immediata de santa Agnès).

El manteniment de l'orgue es fa palès en la compra d'una corda el juliol de $1384^{35}$, i l'equipament librari, en una altra l'octubre de 1400 en referir-se a la nova relligació i enquadernació en pell del llibre que utilitzaven els organistes per acompanyar el cant $^{36}$.

${ }^{33}$ ACB-O, Llibre de 1385-1387, f. 48: «Item pague a-n Bernat Moragues, fuster, per $\mathrm{I}$ jorn [e] mig que adobà la trapa sobre los òrguens, e mes drap en la finestra del croer dels òrguens, VI s. Item pague al dit Bernat per $I^{a}$ taula de fuyla levada obs de la dita trapa a cubrir, XIII s. Item pague a n'Anthoni Alamany, fuester, per II jorns que fo a la dita faena, qui a preu de III s. VI dr. munten VII s. Item pague per drap, veta e taxes obs de la dita finestra, qui costà VI s.).

${ }^{34}$ ACB-S, Llibre d'administració de 1389-1391, f. 80: «ltem fiu agranar e denejar lo croer sobre la capella de Sent Lorens, e acò per lo mestre dels òrgens, qui y posà los canons dels òrgens majors, IIII s.m.

${ }^{35}$ ACB-S, Llibre d'administració de 1383-1385, f. 67: «Item compre 1 troç de corda de cànem per obs dels òrgens, costà III s.m.

${ }^{36}$ ACB-S, Llibre d'administració de 1399-1401, f. 15: «Item [a Guillem Mascharó, convers] li fiu ligar e cobrir de cúy lo libre de cant qui servex als drguens, costà II s.s. 
Com a conseqüència del periode critic que travessà l'orgue major a partir de 1383, o bé d'una moda que s'imposava arreu, o tal volta de les dues raons alhora, el capítol barceloní decidí de dotar la seva catedral d'un orgue petit, que de moment situaren a l'indret de la trona a tocar el cor. Sembla que la seva posada al punt donà molts maldecaps i que la seva història anava unida a la Sagristia Menor, benifet que institucionalment vetllava el culte de san Oleguer.

Denominem aquest aparell musical amb l'adjectiu menor, perquè expressa millor la contraposició a major i perquè la documentació dels segles posteriors en farà molt ús. Els adjectius que, en canvi, es troben utilitzats en els dos documents que l'esmenten són «parva» i «pochs», en el significat clar de petit, oposat a gran. No cal dir que l'expressió literària relativa a l'orgue menor sempre és en plural, a l'estil de «òrguens majors», dels quals es diferenciaven en la grandària $i$, per consegüent, en el nombre d'elements. Condicionament que no és identificable necessàriament amb el de ser canviable de lloc amb facilitat, més propi dels mobibles i transportables (i ben diferents dels dits de coll, penjats a semblança d'un sac de gemecs). Almenys, la documentació no ho abona, sinó que convé més a un instrument fix. Serà unes desenes d'anys després que pot parlar-se de diversos orgues menors, aixi com d'orgue mitjà, a la catedral de Barcelona. En els treballs publicats anteriorment, s'assenyala l'any $1437 \mathrm{com}$ el de la nota més antiga sobre l'orgue menor; tret de FẢBREGA, que publica la hipòtesi del 1385 . Nosaltres assegurem definitivament aquesta data com a any de la seva construcció.

La comanda capitular d'un orgue menor fou concertada l'any 1385 amb l'orguener Pere Devesa, «mestre de struments de Barçalone». Ell va emprendre, diu la nota documental,

de fer uns òrguens nous en la Seu,

orgue que identifiquem amb el menor, atès que el 1390 un d'aquesta categoria ja funcionava, malgrat que era objecte de 
reparació i que li faltava la cadira. Degué treballar en la seva construcció els mesos d'estiu i tardor de 1385, i cobrà 80 lliures; temps i preu que s'acosten molt als especificats en la gran renovació de l'orgue major el 1345. Els diners, en absència d'un benefactor, foren bestrets del fons de les capes, és a dir, l'ornament litúrgic que cada canonge nou havia de lliurar a la Seu en ocasió del seu ingrés en el cos capitular barceloní, o l'import equivalent pagat sovint fraccionadament, que pujava a 20 lliures. El mestre, d'aquest fons, en cobrà 80 lliures, 60 de les quals les cobrà el 28 de juliol i 20 el 18 de novembre d'aquell any $1385^{37}$. El 1390 la catedral disposava ja d'orgue, el de Pere Devesa segurament; el document l'anomena petit, en l'expressió «òrgens pochs». Tot dóna a entendre que es tractava d'una novetat d'aquell any o de l'anterior; llavors es construïa encara la cadira. Aquest accessori, indispensable, denominat trona en el document, l'obraren en fusta i el recobriren de llistons de fusta pintada. La seva construcció, en un periode indeterminat de 1389-1391, ocupà tres mestres fusters i un jove durant tres dies, i costà entre tot 8 lliures, 4 sous i 4 diners $^{38}$. Un treball, doncs, de certa importància.

${ }^{37}$ ACB-S, Llibre de les capes, f. 29. El fons de les capes dels canonges Gil Corts, Bernat Serra, Pere Roca i Guilhem Agrafulha - «cardenal d'Agreful» titular de Sant Esteve sin Coelio monten i canonge barceloní en temps del Cisma d'Occident-, servi per pagar les despeses de l'orgue menor. Reproduïm la part inicial de la primera de les dues notes, que diu: «Item a XXVIII del mes de juliol del dit any [1385] doní en Pere Devesa, mestre de struments de Barçalone, lo qual à enprès de fer uns òrguens nous en la Seu...», Al mateix llibre, vegeu els advertiments anotats coetàniament a la secció de cada canonge, f. $27,27 v$ i $28 v$. Tres d'ells eren difunts el 1385.

${ }_{38}$ ACB-S, Llibre d'administració de 1389-1391, f. 49v. L'apuntament és un xic llarg: "Item féu fer mossèn Berenguer des Feu una trona de fust per los órgens pochs: compre nou taulas de quart a raó de VI s. VI dr. la peça, munten II II. XVIII s. VI dr. Item compre nou cabirons de terz a raó de IIII s. la peça, munten I* II. XVI s. Item compre una XII ${ }^{\text {na }}$ de listons pintats, costaren XI s. Item costà de port la dite fuste I s. II dr. Item costà I C [un centenar) de punxas per punxar los dits listons, VI dr. Item costaren claus dinals e mayals, barcharols e taulars, $\mathrm{X}$ s. IIII dr. Item costaren III mestres qui obraren III jorns, a raó de IIII s., munten $1^{*}$ II. XVI s. Item costà I jove qui obrà III jorns, a raó de III s. VI dr., munten X s. VI dr. Item compre bigas e empe- 
Un mestre d'orgues foraster, que completa l'obra de Devesa, hi esmerçà molt més de temps en una feina que qualifiquem de posada al punt definitiva. Cobrà 20 florins, que es convertiren en el doble de resultes d'un donatiu graciós d'import igual que, contents, li feren el bisbe i el capitol, segons consta en el document de l'àpoca que porta la data de 19 d'octubre de 1390:

Solvistis michi quadraginta florenos auri aragonenses racionibus sequentibus, videlicet, viginti florenos pro reparacione organorum parvorum dicte sedis, et viginti florenos quos reverendus dominus Barchinone episcopus et venerabile capitulum sedis predicte michi graciose concesserunt et per vos prefixe nomine dari et solvi mandarunt.

L'orguener és especificat en el document com a magister organorum i se l'anomena amb la fórmula magister Franciscus Ispalensis, pròpia de personas enteses i eminents en la seva ciència. Aquest Francisco Hispalense treballà en l'orgue petit de la catedral a finals d'estiu i principis de tardor en una tasca denominada «reparació»» i que consistia en l'acabament definitiu de l'instrument iniciat el 1385. El pagament fou a càrrec del conegut canonge Berenguer Feu, en qualitat de regent de la Sagristia Menor, el qual ho bestregué del diner que havia percebut en establir un obrador del carrer de la Freneria, a l'armer Ramon Badia, ciutadà de Barcelona ${ }^{39}$.

Aquest orgue menor, passats set anys del darrer endegament, necessità una atenció molt forta de conservació, amb inclusió d'arranjament de peces que no rutllaven, que fou encomanada a fra Pere Creu, monjo del monestir de Santa Maria de Ripoll. Amb data de 23 d'agost de 1397 consta el document de l'àpoca de 50 florins, quantitat notable certament, en els següents termes:

Quod solvistis et numerando tradidistis michi bene et plenarie ad meam voluntatem quinquaginta florenos auri aragonenses pro reparacione quam ego feci in organis dicte Sedis,

ralts per la dita trona, qui costaren $1^{2}$ II. I s. IIII dr. Munten VIII II. IIII s. IIII dr.».

${ }^{39} \mathrm{ACB}$, perg. 3-6-35. Publiquem el text complet a l'apèndix 3. 
on la citació genèrica orgue - referible, doncs, a l'orgue major i al menor, o als dos - pren el sentit complet en trobar com a pagador el regent de la Sagristia Menor, el prevere Antoni $\mathrm{Gual}^{40}$, lligam que en el precedent document està relacionat expressament amb l'orgue menor.

Aquest orgue el situaren a la trona, no simplement al costat o en aquell indret, sinó a l'espai de la trona pròpiament dit, i col-locaren un pany a la porta d'accés, segons es dedueix d'un apuntament escrit el 19 de juliol de 1391:

Item lo dit die compre un pay (sic) d'en Alamany, farrer, per ops dels òrgens, qui stan en la trona, costà III s. VI dr. ${ }^{4}$,

en l'original del qual l'escrivent tingué una atenció extrema de posar "stan en la trona», en què "en» és escrit a l'interlineat en substitució del mot original «denant», que ratllà. Uns mesos després, gener de 1392, dotaren l'instrument de quatre francisses, en substitució o no d'unes antigues, que costaren 8 sous $^{42}$.

En el període mencionat de 1389-1391, ocupant el darrer lloc dels quatre apuntaments registrats en la mateixa secció, llegim que

Item done a IIII bastanys qui aportaren los òrgens de casa d'en Bernat Solsas a la Seu, $1 \mathrm{~s}$. VIII $\mathrm{dr}^{43}$

que potser dóna a conèixer l'obrador en el qual Pere Devesa construí l'orgue petit; res no és contrari, però, a pensar en la reparació d'un cos de l'instrument o en un orgue prestat a la Seu.

\section{ORGUES PORTÀTILS EN PRÉSTEC}

Les deficiències de l'orgue major, remarcables sobretot els anys 1385 i 1389-1390, quan la catedral encara no disposava d'un se-

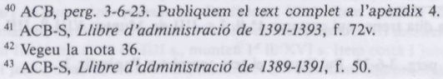


gon orgue, inclinaren el capitol a suplir el buit a còpia de sol-licitar el préstec d'orgues que fossin transportables, $\mathrm{i}$ acudiren al rei i al monestir de Pedralbes, que en dísposaven.

Lorgue movible reial, que només havia de traspassar el carrer estret entre el palau reial i la porta de sant Iu (dit dels Comtes actualment), efectuà el trajecte dues vegades. La primera fou un dia de setembre de l'any 1385, amb permís del rei Pere el Cerimoniós, i intervingueren en el transport sis homes:

Item done a VI bastays, qui aportaren les òrgens del senyor Rey del seu palau a la Seu, IIII s. II $\mathrm{dr}^{44}$

L'estada a la seu durà bastant perquè als deu mesos es portava a terme la reparació de la manxa, com ho testimonia la nota següent registrada el mes de juny de $1386^{45}$ :

Item done a-n Andreu Pascal per adobar la manxa dels òrgens, los quals lo senyor Rey prestà a la Seu, ço és, per una aluda e per I tornet de ferre, II s. VI dr.

Aquesta nota deixa constància de la intervenció de l'organista Pasqual en una reparació de l'orgue rebut en préstec, en un dels períodes del seu contracte amb el capítol.

Lorgue reial menor, per segona vegada, travessà el carrer un dia inespecificat de l'any $1390 \mathrm{i}$, segons l'enregistrament comptable:

Item done a mossèn Berenguer des Feu, los quals ells donà $\mathrm{a}$ I bon hom Parteguelles, menstre d'òrgens, qui tractà que la Seu hagés los orgens menors del senyor rey en Johan, VI florins = III II. VI s, ${ }^{46}$

es considerà necessari de demanar la intervenció de l'orguener Parteguelles, a fi d'aconseguir la vènia del rei Joan I; intervenció que el capítol regracià amb esplendidesa.

${ }^{44}$ ACB-S, Llibre d'administració de 1385-1387, f. 57.

${ }^{45}$ Id., ib., f. 63.

${ }^{46}$ ACB-S, Llibre d'administració de 1389-1391, f. 50. 
L'altre orgue rebut en préstec, en canvi, havia de recórrer un llarg camí, des de Pedralbes, i tenia al seu favor unes dimensions més reduides que aquell, ja que amb quatre homes n'hi hagué prou per al seu trasllat. Estigué a la Seu, si no tota la tardor, durant les festes de Nadal-Reis de 1389-1390, i un dia de finals de gener $\mathrm{o}$ de primers de febrer es registrà la notícia següent ${ }^{47}$ :

Item done a IIII bastays, qui aportaren los òrgens a Pedralbes, los quals havien prestat a la Seu, I II. IIII s.,

en què l'import del sou és en correspondéncia a la distància $\mathrm{i}$ al temps passat en el transport.

Aquests són els dos orgues que la catedral sol-licità en préstec, mentre l'orgue major no anava bé del tot i es posava en funcionament l'orgue petit. Hem fet referència ja a l'orgue que sortí de la casa de Solsas i que cal identificar amb l'orgue petit nou, o bé amb un d'aquests prestats o bé amb un tercer.

\section{REMARQUES}

A la vista de les afirmacions contingudes als paràgrafs precedents contrastables amb la documentació publicada al cos de l'estudi, a les notes o a l'apèndix, convé posar en relleu unes precisions que esmenen algunes inexactituds estampades al treball d'altres autors.

La majoria d'autors es refereixen al primer benefactor Guillem de Lacera i el cataloguen de beneficiat de santa Agnès a la Seu i afirmen que testà el 1259. La documentació, però, testimonia: que en el moment de fer construir l'orgue catedralici era simplement un ciutadà barceloní; que el 1259 ordenà la fundació del benifet de santa Agnès a la catedral, fent constar entre les obligacions del clergue obtentor la inversió d'unes despeses anuals en la conservació de l'orgue que ell havia llegat a la Seu; que ingressà a l'orde de sant Agusti en la canònica de santa An-

47 Id, ib., f. 77. 
na de Barcelona; i que, en el moment del seu ingrés el 1263 dictà el seu testament.

La datació de l'obra de Berenguer Pla suscita dubtes, com hem dit, a I'hora de situar-lo cronológicament: nosaltres el posem en 1317-1320, ben lluny de l'afirmació d'un dels autors (BALDELLÓ) quan escriu que «a mediados del siglo XIII» treballà en la construcció de l'orgue, basat en uns «documentos inéditos del Rdo. J. MAS", que no ho afirmen.

Un tercer punt conflictiu és el relatiu a l'orguener «N. Antonet». Un autor (BADELLO) el posa a principis del segle XIV i remet a una altra publicació. En aquesta (en anglès), però, no es fa tal afirmació, sinó que resumeix correctament les dades que donà a conèixer mossèn Mas, qui sobre això escriu: «Als òrguens majors hi féu algun adob en 1392 En Jacme Ballester, los quals sembla qu'eren los que fabrià $\mathrm{N}$. Antonet y que pera pagarli los trevalls lo Capitol nomenà una Comissió pera manllevar 65 lliures y 14 sous»). Un text, com es veu, redactat en uns termes no gaire clars i que són el resultat del farciment indegut d'una fitxa al mig d'una altra. Com que el fet d'esbrinar la veracitat no deixava de suscitar un interès evident, els passos indagadors ens portaren a llegir les paperetes inèdites de mossèn Mas sobre la Seu, que encara no han estat aplegades en volums, com les de la ciutat $\mathrm{j}$ els pobles del bisbat, que són de més fàcil consulta. Entre les fitxes, n'hem trobat una que remet a un manual notarial de l'Arxiu Capitular de Barcelona, on consta el títol d'un sindicat atorgat el 21 de juny de 1483 als canonges Lluís Sirvent i Gaspar Peiró per poder manllevar 65 lliures i 14 sous per pagar a N'Antonet, mestre d'orgues, el seu treball de fabricar l'orgue major de la Seu, sindicat revocat el 18 de juny de $1494^{48}$. Per tant, Antonet és un orguener de final del segle xv: Antoni Prats.

48 ACB, Notaria, Dalmau Ginebret, Manual de 1483-1485, f. 8 . Sols hi consta l'encapçalament i la nota de revocació, i la resta és en blanc - fet molt usual en els registres notarials. Sobre el nom de l'orguener, a la rúbrica es llegeix (nnantonet», en el que la «n») és l'abreujament del títol de cortesia (cen», però no la ínicial d'un nom com ho interpreta Mn. Mas en el seu treball ( $\mathrm{N}$. Antonet»). Es refereix a Antoni Prats, citat sovint en la documentació amb el revestiment familiar d'Antonet, qui inicià la construcció de l'orgue el 4.5.1482 (Cf. ACB-O, Llibre de 1481-1483, f. 140). 
Per acabar, mossèn Mas es referí a un orgue situat a la capella de santa Eulàlia: «A derreries del segle XIV ja hi havia orga a dita capella, deduintse de les notes arxivades que's fabricà en 1494», amb una evident contradicció entre segle i any; a les seves notes inèdites no hem trobat cap fitxa que abans del 1400 parli de l'orgue de santa Eulàlia, com tampoc no ha sortit al curs de la nostra investigació.

\section{CONCLUSIONS}

En breus paraules, la investigació permet presentar les següents conclusions ben fonamentades documentalment en els segles XIII i XIV:

- La història documental dels orgues de la catedral de Barcelona comença el 1259.

- Dos eren els orgues: major i menor, que hi hagué des de l'any 1385.

- Podem parlar de l'orgue de Guillem de Lacera (1259), de Berenguer Desplà (1317), de Martín Ferrándiz (1345) i del bisbe Guillem de Torrelles (1368).

- L'orgue major fou reparat diverses vegades a partir de 1385 , amb la intervenció dels orgueners Antoni Rovira (1383), Pere Devesa (1389) i d'un mestre de Manresa (1389-1390).

- Sabem els noms de tres organistes: Antoni Gran (1377-1392), Adreu Pasqual (1379-1391) i Jaume Ballester (1378-1403).

- Sobre l'orgue menor, consta el constructor principal: Pere Devesa (1385), el disposador final: Francisco Hispalense (1390) i un reparador: fra Pere Creu (1397).

- A la catedral sonaren també, prestats, un orgue del rei (13851386 i 1390) i un de Pedralbes (1389-1390). 


\section{APÈNDIX}

$\mathrm{Al}$ costat de l'estudi de la documentació descoberta, l'interès del treball present se centra en la publicació de tots els textos relacionats amb la història dels orgues de la catedral de Barcelona dels segles XIII i xIv, atès que no són gaires en nombre i que es tracta d'apuntaments breus generalment. Aquests van recollits entre el cos de l'estudi i les notes. Aquí s'apleguen només quatre documents un xic llargs, entre els quals hi ha el contracte de Martín Ferrándiz, una peça de cabdal importància en la història universal dels orgues.

\section{I}

19 juliol 1345

El bisbe i el capitol de Barcelona donen plenes facultats als canonges Guillem de Torrelles i Ferrer Peiró per fer reparar l'orgue de la Seu o per fer-ne fabricar un de nou, ara que han trobat un expert en aquesta feina, mestre Martín Ferrándiz, i els indiquen que per sufragar les despeses tenen a la seva disposició tres administracions capitulars.

Institut Municipal d'Història de la ciutat de Barcelona, Paperetes de mossèn Josep Mas, Seu de Barcelona, capsa 23, aplega Orga. És una transcripció feta a llapis amb esmenes sobreposades, desproveida de les subscripcions. Les indicacions sobre la procedència arxivística (1343-45, f. 99 - Not. Cap.) no ens han permès de descobrir I'original en els fons documentals de l'Arxiu Capitular de Barcelona. Al nostre concepte, el document no ofereix cap dubte sobre el seu valor, malgrat que la transcripció no sigui clara en algunes paraules. La presentem amb alguns retocs nostres.

Frater Bernardus, etc., et capitulum eiusdem ecclesie, venerabilibus et prudentibus viris Guilelmo de Turriliis et Ferrario Peyroni, ipsius ecclesie canonicis. Salutem in Domino Jhesu Christo. Cum predicta ecclesia defectum notabilem organorum habeat, que multum decorant divinum officium evidenter, iamque diu est vobis, vivente domino fratre Ferrario bone memorie Barchinone episcopo, per ipsum et vos capitulum vobis commissum fuistis, ut ipsa feceretis organa fieri de novo vel vetera in predicta sede existencia, si fieri potuissent prout convenit, reparari; nunc autem repereatis, prout fertur, magistrum Martinum Ferrandis, qui expertus [est] in dicto opere sicut percepimus [per nos] vel per aliquos fidedignos. Idcirco per vos ipsa organa reparari vel de novo fieri facere, prout melius discretioni vestre videbitur faciendum, licite valeatis ad expensas Caritatis et Subsacristie ac Operis ecclesie equis partibus dividendas, vobis utrique vestrum in solidum plenam presentibus concedimus facultatem. Mandantes tenore dicta- 
rum presencium procuratoribus dicte Caritatis ac Subsacristie [et Operis] memorate ecclesie vel loca tenentibus eorumdem, ut vobis pro dictis reparandis vel fiendis noviter organis expensas, quas fecieritis et necessarie fuerint, debent equis ut predicitur partibus ministrare. Nos enim volumus et eciam ordinamus, quod ab ipsis Subsacristie, Caritatis et Operis procuratoribus, nomine nostro compota audientes, expensas hiusmodi in eorum compotorum impendant et administrent, non expedita a nobis alia litera seu mandato. In cuius rei testimonium presentem literam impressione sigillorum nostrorum inferius communiri [decrevimus]. Datum Barchinone XIIII kalendas augusti anno Domini milesimo CC XL quinto.

\section{3 juliol 1345}

Ferrer Peiró, en nom del company de comissió Guillem de Torrelles $i$ del bisbe i capitol de Barcelona, pacta amb Martín Ferrándiz, mestre d'orgues de Toledo, la construcció d'un orgue per a la Seu amb unes condicions concretes, pel preu de 80 lliures barcelonines, a més de l'import de la manutenció $i$ sense comptar els materials $i$ la feina de fuster, estany i plom.

\section{ACB, Obra, pergami 3 .}

Noverint universi, quod ego Ferrarius Peyroni, canonicus Barchinone, comissarius ad faciendum fieri de novo in Sede Barchinone organa, vel vetera in predicta Sede existencia reparari, una cum venerabili et discreto Guillermo de Turrillis, canonico Barchinone, et in solidum deputatus a reverendo in Christo patre et domino domino fratre Bernardo, miseracione divina Barchinone episcopo, et a venerabili capitulo Sedis Barchinone, prout de hiis apparet per quandam litteram papiream sigillis dictorum domini episcopi et capituli in dorso sigillata, que data fuit Barchinone quartodecimo kalendas augusti anno infrascripto, et procurator eciam ad infrascripta specialiter constitutus a dicto venerabili Guillermo de Turrillis, absente, cum publico instrumento facto per notarium infrascriptum undecimo kalendas augusti anno infrascripto, nomine dictarum comissionis et procuracionis ex una parte, et ego Martinus Ferrandiç, civis Tholetane, magister organorum, nomine meo proprio ex altera, confitemur et recognoscimus nobis ad invicem, quod pacta et convenciones, que in infrascriptis capitulis continentur, fuerunt iurata et conventa inter nos prout inferius continentur. Tenores vero dictorum capitulorum tales sunt. És emprès entre los honrats en Guillem Torreles e en Ferrer Peyró, canonges de la Seu de Barchinona, d'una part, avent loch açò del senyor bisbe e del honrat capitol de la dita Seu, e en Martí Ferràndiç, de Toledeu, maestre de òrguens, 
de la altra, que lo dit mestre Martí faça uns òrguens a obs de la dita Seu en los quals faça tres vies de punts al través més que no eren en aquels que ja eren en la dita Seu, los quals obrà en Berenguer des Pla, beneficiat en aquela. Item hi faça més de VII tro en VIII de migs puns. Item que faça en la terça part primera de les vies dels punts en cascuna via XII canons, exceptat en les IIII vies primeres hon stan los bordons en què no aya mas VII canons en cascuna via. Item en la segona part farà en cascuna via dels punts XVI canons. Item en la terça part farà en cascuna de les vies dels punts XX canons. Axí que los canons dels dits òrguens muntaran [sic]. Item farà la caxa a obs dels dits òrguens de bona e bela e secha fusta, ab obratge pla, e axi matex la cuberta e tota la altra obra que serà de fusta. Item farà les manxes ab bones postz e fermes, e de bons cuirs de cervo, e bé adobats. Item farà les claviles per les quals se toquen los òrguens totes de fust de box e de gingoler, bones e ben fermes, e les mols bones e stables. Item prometrà ab sagrament que ell farà la dita obra bona e sonorosa e ferma e stable, de tot son saber e poder, e posar sa pena de càrser en poder del officiall de Barchinona, que Is dits òrguens farà dins Barchinona contínuament, e que nula altra obra de òrguens no farà sens licència dels demuntdits en Guillem de Torrelles i en Farrer Payró, o de la I d'éls, dentrò que'ls dits òrguens sien acabats complidament e posats là bon los dits en Guillem Torrelles o.n Farrer Payró li ordonaran per nom del dit senyor bisbe e capitoll. E tota la obra dels dits òrguens farà ab ses messions tro sien as-tiatz en la dita Seu, e los dits honrats en Guillem Torrelles e en Farrer Payró per nom del senyor bisbe e capítoll de Barchinona daran per preu dels dits orguens al dit maestre Martí LXXX libras, de les quals li paguaran ço que costarà estayn, plom, fusta, cuirs e totes altres coses que aja mester a obs de la obra. Item li bestrauran a pagar los maestres qui li obraran en lo plom, sta e fusta de la dita obra. Item li paguaran cascun mes a obs de sa despesa XL solidos, del dia que comensarà trop a cap de I an complit, que entenen que la obra sia acabada. Item li pagaran adés de present de la dita quantitat $\mathrm{C}$ solidos. $\mathrm{E}$ con los dits òrguens complidament sien acabats e posats en la Seu paguaran al dit maestre Martí tot ço que romandra de les dites $\mathrm{LXXX}$ libras. Et ideo gratis et ex certa sciencia ego dictus Ferrarius Paroni [sic], nominibus predictis, ex una parte, et ego dictus Martinus Ferrandiç, ex altera, gratis et ex certa sciencia convenimus et promittimus nobis ad invicem, videlicet una pars alteri, quod predicta omnia et singular, prout superius dicta sunt et expressa, attendemus et complebimus et tenbimus et observabimus, et quod in aliquo non contraveniemus aliquo iure causa vel eciam racione. Et pro hiis complendis obligamus nobis ad invicem, videlicet, ego dictus Ferrarius Payroni nominibus predictis ominia bona dictorum domini episcopi et capituli, et ego dictus Martinus Ferrandiç, omnia 
bona mea mobilia et immobilia, habita et habenda. Et ut predicta maiori gaudeant firmitate, ego dictus Martinus Ferrandiç, non vi nec dolo, set sponte iuro per dominum Deum et eius sancta quatuor evangelia manibus meis corporaliter tacta, predicta attendere et complere, et in aliquo non contravenire aliquo iure, causa vel eciam racione. Hec igitur que dicta sunt facimus, paciscimur et promittimus, scilicet, ego dictus Ferrarius Payroni nominibus predictis vobis dicto Martino Ferrandiç, et ego dictus Martinus Ferrandiç vobis dicto venerabili Ferrario Payroni et vobis eciam notario infrascripto tanquam publice persone pro utraque parte. Et pro aliis eciam personis quarum interest et intererit recipienti et paciscenti ac eciam legittime stipulanti. Actum est hoc decimo kalendas augusti anno domini millesimo trecentesimo quadragesimo quinto. Sig + num Ferrarii Peyroni. Sig + num Martini Ferrandiç, predictorum qui nominibus predictis hec laudamus et firmamus, et ego dictus Martinus Ferrandiç iuro.

Testes hiuus rei sunt discretus Guillermus Vilella, rector ecclesie Sancti Genesii de Amigdalo, Galcerandus de Finestris et Franciscus de Montepavone, causidicus, civis Barchinone.

Sig + num Petri Borrelli, auctoritate regia notarii publici Barchinone, qui hec scribi fecit et clausit cum litteris suprapositis in linea octava ubi dicitur part, et in linea vicesima prima ubi dicitur utraque parte. Et cum litteris rasis et emendatis in linea quartadecima ubi dicitur cuirs, et in linea vicesima secunda ubi dicitur nominibus.

\section{9 octubre 1390}

Francisco Hispalense, mestre d'orgues, fa fe que de Berenguer Feu, canonge tresorer i regent de la Sagristia Menor de la catedral de Barcelona, ha rebut 40 florins d'or aragonesos, 20 dels quals en concepte de paga pel treball de reparar l'orgue menor de la dita Seu $i 20 \mathrm{com}$ a donatiu graciós del bisbe i capitol.

ACB, Sagristia Menor, pergami 35.

Sit omnibus notum, quod cgo magister Franciscus Ispalensis, magister organorum, confiteor et recognosco vobis venerabili Berengario de Feudo, canonico thesaurario ac regenti Minorem ecclesie Sedis Barchinone, una cum venerabili Guillelmo Alanyani, canonico dicte Sedis, quod ex illis undecim mille ducentis solidos monete Barchinone de terno, pro quibus seu intrata quorum stabilivistis et in emphiteosim concessistis Raymundo Badia, armerio, civi dicte civitatis, et suis et quibus voluerit perpetuo suis tam consimilibus et suorum, quod- 
dam hospicium cum tribus portalibus extra in via publica apparientibus et cum introitibus, exitibus, iuribus et perinenciis suis, situm in vico de la Freneria, cum instrumento publico de dicto stabilimento facto in posse subscripti notarii die XVII ${ }^{2}$ marcii anno a nativitate Domini millesimo trecentesimo nonagesimo, solvistis michi quadraginta florenos auri aragonenses racionibus sequentibus, videlicet, viginti florenos pro reparacione organorum parvorum dicte Sedis, et viginti florenos quos reverendus dominus Barchinone episcopus et venerabili capitulum Sedis predicte michi graciose concesserunt, et per vos prefixe nomine dari et solvi mandarunt. Et ideo renunciando excepcioni dictorum florenorum non habitorum et non receptorum et doli, facio vobis de predictis quadraginta florenis presens apoche instrumentum in testimonium veritatis. Volens eciam et consenciens, quod de hiis possint fieri duo publica consimilia instrumenta, quorum unum vobis, alterum vero dicto Raymundo Badia ad conservacionem iuris utriusque tradatur per notarium infrascriptum. Actum est hoc Barchinone, XIX ${ }^{a}$ die octobris anno a nativitate Domini millesimo trecentesimo nonagesimo. Sig + num Francisci Ispalensis predicti, qui hec laudo et firmo.

Testes huius rei sunt Franciscus Baiuli, notarius, et Petrus Laurencii, scriptor, cives Barchinone,

Sig + num Johannis Eximini auctoritate regia notarii publici Barchinone, qui hec scribi fecit et clausit.

\section{3 agost 1397}

Fra Pere Creu, monjo del monestir de Santa Maria de Ripoll, fa fe que d'Antoni Gual, prevere i regent de la Sagristia Menor de la catedral de Barcelona, ha rebut 50 florins d'or aragonesos pel seu treball de reparar l'orgue de la dita Seu.

\section{$A C B$, Sagristia Menor, pergamí 23, documenta.}

Sit omnibus notum, quod ego frater Petrus de Cruce, monachus monasterii Beate Marie de Rivipullo, diocesis vicensis, confiteor et recognosco vobis discreto Anthonio Gual, presbitero, regenti Sacristiam Minorem Sedis Barchinone, quod solvistis et numerando tradidistis michi bene et plenarie ad meam voluntatem quinquaginta florenos auri aragonenses pro reparacione quam ego feci in organis dicte Sedis. Et ideo renunciando excepcioni non numerate et non solute peccunie et doli, facio vobis dicto nomine et vestris de predictis quingaginta florenis presentem apocham de soluto. Actum est hoc Barchinone, vicesima tercia die augusti anno a nativitate Domini millesimo trecentesimo no- 
nagesimo septimo. Sig + num fratris Petri de Cruce predicti, qui hec laudo et firmo.

Testes huius rei sunt Anthonius Stapera, notarius, civis, et Dominicus de Molinos, scriptor, Barchinone.

Sig + num Jacobi Rosselli auctoritate regia notarii publici Barchinone, qui hec scribi fecit et clausit. 